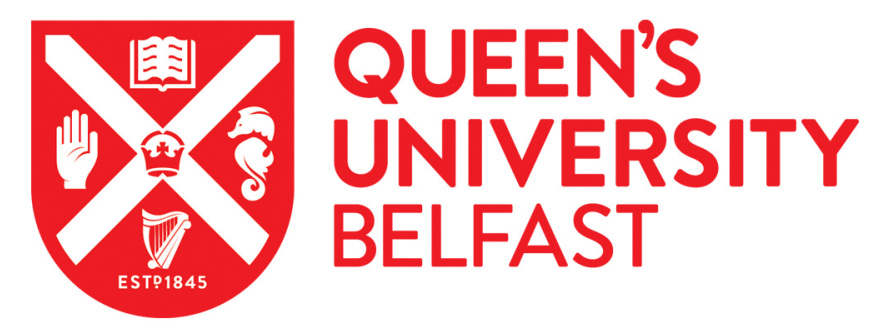

\title{
Improving healthcare access for people with visual impairment and blindness
}

Cupples, M., Hart, P., Johnston, A., \& Jackson, A. J. (2012). Improving healthcare access for people with visual impairment and blindness. BMJ (Clinical Research Edition), 344(7842), [e542]. https://doi.org/10.1136/bmj.e542

\author{
Published in: \\ BMJ (Clinical Research Edition)
}

Document Version:

Publisher's PDF, also known as Version of record

Queen's University Belfast - Research Portal:

Link to publication record in Queen's University Belfast Research Portal

Publisher rights

(c) BMJ Publishing Group Ltd 2012. This work is made available online in accordance with the publisher's policies. Please refer to any applicable terms of use of the publisher.

\section{General rights}

Copyright for the publications made accessible via the Queen's University Belfast Research Portal is retained by the author(s) and / or other copyright owners and it is a condition of accessing these publications that users recognise and abide by the legal requirements associated with these rights.

Take down policy

The Research Portal is Queen's institutional repository that provides access to Queen's research output. Every effort has been made to ensure that content in the Research Portal does not infringe any person's rights, or applicable UK laws. If you discover content in the Research Portal that you believe breaches copyright or violates any law, please contact openaccess@qub.ac.uk. 


\title{
CLINICAL REVIEW
}

\section{Improving healthcare access for people with visual impairment and blindness}

\author{
M E Cupples clinical reader ${ }^{1}$, P M Hart consultant ophthalmologist ${ }^{2}$, A Johnston care co-ordinator ${ }^{3}$, \\ A J Jackson head of optometry ${ }^{2}$ head of clinical services ${ }^{4}$
}

${ }^{1}$ Department of General Practice, Queen's University, Belfast BT9 7HR, UK; ${ }^{2}$ Belfast Health and Social Care Trust, Belfast; ${ }^{3}$ Royal National Institute for the Blind, Belfast; ${ }^{4}$ Australian College of Optometry, Melbourne, Australia

\begin{abstract}
Worldwide, visual impairment is increasing in prevalence: current data indicate that 284 million people have impaired vision, ${ }^{1} 10 \%$ of whom live in the developed world. In the UK sight loss affects about two million people, ${ }^{2}$ including an estimated 80000 of working age and 25000 children. The prevalence of visual impairment is higher among those with multiple disability and older people. ${ }^{3}$ According to estimates from the UK's Royal National Institute for the Blind (RNIB) one in 30 people of any age, one in five aged 75 or over, and half of those over age 90 years in the UK are living with sight loss. ${ }^{4}$ Older people with vision impairment report greater difficulty performing activities of everyday living than those with other or no sensory impairments. ${ }^{5}$ Individuals with impaired vision may have great difficulty in accessing and negotiating healthcare services. We discuss the difficulties that visually impaired patients encounter in the healthcare environment and ways in which problems may be overcome.
\end{abstract}

\section{What is the range of visual impairment?}

People who are registered as severely sight impaired (previously known as blind registration) are defined as having central visual acuity of less than $3 / 60$ with normal fields of vision, or gross visual field restriction. They cannot see at $3 \mathrm{~m}$ what the normally sighted person sees at $60 \mathrm{~m}$. Those registered as sight impaired (previously known as partially sighted) can see at $3 \mathrm{~m}$, but not at $6 \mathrm{~m}$, what the normally sighted person sees at $60 \mathrm{~m}$. Less severe visual impairment is not captured by registration data, and its prevalence is difficult to quantify. People classified as having low vision have a visual acuity of less than $6 / 18$ but more than $3 / 60$. They are not eligible to drive and may have difficulty recognising faces across a street, watching television, or choosing clean, unstained, co-ordinated clothing.

\section{What effect does visual impairment have on the individual?}

If loss of vision is gradual, individuals may adapt better to changed circumstances than if it is sudden. However, regardless of the mode of onset, many who experience loss of vision withdraw from social contact, ${ }^{6}$ perhaps partly because they lose awareness of the nuances of body language that are part of social interactions. A patient's fear of experiencing "total darkness" may be associated with profound psychological distress. For older patients, losing physical mobility and other senses such as hearing and touch adds to a sense of difficulty and isolation and may lead to poor mental health, which in turn may affect families. ${ }^{7}$ An increased risk of depression, ${ }^{8}$ suicide, ${ }^{9}$ falls,,${ }^{10}$ and cognitive decline ${ }^{11}$ may be exacerbated if healthcare providers do not recognise the particular problems of people with visual impairment. Previously identified problems ${ }^{12}$ include receiving written information in inaccessible formats, difficulties communicating with practitioners and staff, doctors failing to respect people's ability to participate in their own care, and physical difficulties with getting around healthcare facilities. Challenges in obtaining safe, effective, and timely care have been reported; common courtesy and an approach to communication tailored to the individual could improve patients' experiences. $^{12}$

People who lose their vision, especially in later life, may attempt to conceal it, although their ability to do so may vary. They may develop good social support networks, with family members or friends on whom they depend as a confidante for information, directions, and treatment details. The impact of loss of vision is related to the extent to which resolution (relevant to reading, television viewing), panoramic vision (mobility, safe travel) and contrast detection (face recognition, identifying objects in low light) are affected. Those with severe central vision loss, as in macular degeneration, may still move around confidently, especially in familiar surroundings. Their inability to see facial details or to read may go unnoticed. People with glaucoma, who lose their peripheral vision and experience impaired contrast detection, may find it more difficult to function even in familiar environments.

Vivid, recurrent visual hallucinations (Charles Bonnet Syndrome) are an increasingly recognised feature of visual loss, which may result from impaired visual signals being transmitted 


\section{Summary points}

Visual impairment can have adverse consequences for health and wellbeing, and its prevalence is increasing, especially among older people

People with visual impairment are likely to have limited access to information and healthcare facilities, and to receive sub-optimal treatment because staff are unaware of specific needs related to vision

Being aware that people may have problems with vision is an important pre-requisite for good healthcare

Taking time to communicate effectively about access, facilities, diagnosis, and management plans is necessary; communications, in visual or audio format, should be tailored to individuals' needs

Checking that personal resources are in place to facilitate compliance with treatment plans is essential for good clinical care

\section{Sources and selection criteria}

The material for this article was based on discussion between an optometrist, an ophthalmologist, and a general practitioner, who were engaged in research exploring the needs of people with visual impairment in achieving medication compliance. This work resulted in a personal archive of references reflecting needs of people with impaired vision in accessing healthcare. To ensure applicability of the article to this population we consulted the regional base of the Royal National Institute for the Blind (RNIB) and asked its eye care co-ordinator to ask members of the lay public to share their recent experiences of healthcare services and to identify the best advice to improve care provision in practice.

to the brain. In one recent study ${ }^{13}$ a third of people with low vision had experienced such hallucinations; some had not reported them and others had received inadequate explanations. Warning about the possibility of this phenomenon would help alleviate distress.

\section{How might we recognise that someone has impaired vision in the clinical environment?}

Unlike physical impairment, visual impairment is rarely obvious to a casual observer. A few patients with visual impairment will have a guide dog, some a white cane, and even fewer use electronic navigation aids. Those registered as sight impaired or severely sight impaired should have this documented in their medical records but it may not be readily apparent.

Some people have sufficient confidence and insight to inform those involved in their healthcare about their difficulties but many, especially older individuals, are embarrassed that they can no longer see well. Some may assume that professionals working with them will be aware of their problems. Many will take proffered leaflets politely and sign on dotted lines without understanding what is being agreed to, rather than ask questions. In new situations people may become timid and hesitant. Older people may become confused easily and appear angry or demanding. An individual's behaviour may be perceived as strange and misunderstood without awareness of their impairment.

Health professionals need to be alert to the subtle signs that a patient may be visually impaired. Patients with severe impairment may have difficulty in finding a chair or negotiating furniture, may not make eye contact when conversing, or may not respond when something is handed to them.

\section{How might contact with healthcare services be optimised for patients with visual impairment?}

People with visual impairment may encounter difficulties at any point in their interaction with healthcare services, from identification of a potential problem to the ongoing management of diagnosed illness. Effective communication and anticipation of difficulties are key to avoiding and resolving problems.

\section{Improving delivery of information about appointments and treatment}

\section{Example 1}

The daughter of an 87 year old patient with age related macular degeneration highlights how not being able to read printed information may be a problem: "At the ophthalmology clinic my father was told he had 'wet ARMD' and nothing could be done because he did not attend two appointments and had missed his 'window of opportunity'. The doctor said that all she could do was register him as blind. I told the staff that we had never received previous appointments, but I don't think they believed me. My father keeps asking if I know where the two appointments went, and this upsets me. I feel guilty-if we had attended sooner my father's sight loss might have been avoided. I feel that he thinks this too and blames me."

A review published by the $\mathrm{RNIB}^{14}$ noted that "Receiving inaccessible health information has serious consequences for blind and partially sighted people"-such as the loss of privacy and independence (someone else must read the information for them), potential risks to personal safety (regarding medication), and a loss of ability to make informed choices about healthcare. The example above illustrates the serious consequences of a delayed consultation, which might have occurred because the patient could not read appointment letters. Many people do not admit to friends or family that they have problems with their health or eyesight. It may not be easy to ask for help to find telephone numbers to make appointments, arrange transport to the surgery or hospital, and navigate the process of attendance. People may miss information that is presented in leaflets or posters.

When dealing with patients with visual impairment consider carefully how to share information appropriately with the patient, family, and points of referral. Depending on the patient's level of disability appropriate communication might comprise sending letters in large print, with different font styles, or with background contrast, or offering information in audio format, by telephone, or electronically (email or compact disc), rather than letter. For a very few profoundly affected individuals, Braille letters or information could be needed. Patients should be asked about their supporting network of family or friends and how this can be employed in assisting with their healthcare needs.

Perhaps the primary focus of information provision should be to ensure that information about access to general practitioners' surgeries and clinics is offered in various formats, both visual 
and audio, including large print and computer or web based versions.

\section{Helping patients to navigate unfamiliar environments}

\section{Example 2}

A 50 year old man, registered as severely sight impaired, reports how modern technologies have made things more difficult for him: "Electronic systems have reduced my independence. Signing in on the computer installed at my GP's surgery is not possible and saying that I need help is difficult. It's hard to know if anyone's at the reception desk. Before this someone always greeted me as soon as I went through the door. And then, when I was at accident and emergency, I didn't see the button to open the door. The staff shouted at me to press the button but I couldn't see it."

An initial greeting to everyone entering healthcare premises should include a verbal offer of help. People with visual impairment may require simple clear instructions or personal physical guidance to find their way around. Key points to be aware of when guiding people are shown in box 1. Furniture placement and style, lighting levels, glare reduction, use of contrasting colours, and tactile and dual audio and visual signage are important considerations in improving access.

If patients cannot read signs or observe others they may have difficulty finding their way around healthcare premises. They might not be able to communicate effectively with staff because they cannot see visual cues, gestures, or facial expressions. As clinics and surgeries adopt electronic systems to summon patients, visually impaired patients may find that they miss their slots because they are not "called". Healthcare staff should be alert to recognise those for whom electronic systems, particularly those with visual instructions only, pose problems.

In a clinic situation, come out to the waiting room to call the patient and guide them to the consulting room if necessary. Use accurate and specific language when giving directions or explaining the layout of a room. For example, "the door is on your left", rather than "the door is over there". Remember that the person is unlikely to see non-verbal cues and gestures or information. Take time to explain the layout of a room and describe where things are placed if a patient is obliged to stay in an unfamiliar setting. An example of a consequence of not describing the layout of a bathroom to a blind patient was that he fell, hit his head on the toilet, and incurred a head injury. He was also embarrassed and commented "Never will I forget what I had to go through"; he blamed a lack of staff awareness for his unpleasant experience.

\section{Communication and consultation skills Example 3}

A 27 year old woman with visual impairment secondary to congenital glaucoma describes her experience of consultation with healthcare practitioners: "I was so frustrated at the lack of awareness of staff of the basics of interacting with a person who's blind. Sometimes they would talk to members of my family rather than me. Also, they'd create such a drama over having to guide me somewhere. I just think that with some basic training, this could've been a non-issue. I can understand blind or partially sighted people dreading dealing with health services. I have, myself, missed appointments because I couldn't read the appointment letter or simply didn't know it had come until someone with eyesight happened to visit my house."
Pointers for communicating effectively with people who have visual impairment are provided in box 2 . Asking routinely, "Do you have any problems with vision that I should know about?" could make life easier for many who find it difficult to admit spontaneously to their disability. Do not assume that those with a visual disability have a lesser level of understanding or autonomy than those who can see. Even if patients do not make eye contact, face them and talk to them directly, not through a third person. Introduce yourself and all people present in the consulting room. Explain what you are doing and what you plan to do. Tell the patient if you plan to leave the room. If you are moving from one location to another, offer to guide the person, but also offer a description of the environment so that the patient can choose which he or she would prefer. Extra time may be needed for consultations in order to explain things that might otherwise be communicated in writing, to make a plan for appropriate follow-up and delivery of test results, or to allow the patient to ask questions.

Providing an escort to the location for investigations, making an agreed plan for communication of results, writing clear information in referrals about needs relating to vision, and flagging records for future visits facilitates access to good quality care. Good communication empowers patients and enhances their contribution to concordant management plans.

\section{Example 4}

A 54 year old woman with visual impairment describes a clinic visit that went smoothly: "At a recent clinic visit the registrar met me in the waiting room, walked with me to the consulting room, explained the examination I would have and the tests I'd have done, and checked I understood the plan for getting results. He was great-I found out that he had recently received visual awareness training."

Consider the huge impact of loss of vision and refer to services as appropriate. Be aware that some patients may require increased self confidence to alert staff to their limitations related to vision and offer referral to counselling or assertiveness classes. Also, be prepared to offer referral to a low vision clinic; evidence shows clearly that even after one appointment, difficulty in daily visual tasks decreases. ${ }^{15}$

\section{Example 5}

A 37 year old woman describes her experience with her general practitioner after suddenly losing her vision: "After being registered blind and sent home from hospital without any information I went to see my GP for advice. I was aged 37, had lost my job, my [driving] licence, and most of all my confidence. Even though I was really upset, rather than listening to me, the GP opened a copy of the yellow pages. She told me she was looking for the address of a local sensory support team but that she had no idea what they could offer me, nor how long it would take them to contact me. When they did phone me months later it emerged that the GP had not considered the referral urgent. However, my mental health had deteriorated so much that I was referred urgently to the mental health team-I blame my GP and her lack of awareness for this."

The "Additional educational resources" box lists useful sources of information for healthcare practitioners treating patients with visual impairment or blindness. In most countries advice is available from charities and from professional bodies. Within the UK such sources include the Royal College of Ophthalmologists, the College of Optometrists, the British and Irish Orthoptists Society, and specific support groups such as the Albinism Fellowship, British Retinitis Pigmentosa Society, 


\section{Box 1: Key points for basic guiding techniques}

- If the patient is not familiar with the surroundings, ask politely if they would like to be guided; do not be offended if your offer is not accepted

- Offer your arm for the person to grip just above the elbow (they may prefer to grip your shoulder)

- When guiding someone with sight problems, walk slightly in front, making sure that the pace is not too fast or too slow

- If steps or stairs are involved always state whether they go up or down and give warning of approaching ground level

- Explain changes in ground surface, such as moving from a tiled floor to carpet

- Never guide someone into a seat backwards: instead, describe the chair, place your hand on the back of the chair, and enable the person to orientate themselves into the seat independently

\footnotetext{
Box 2 Tips to improve healthcare for patients with visual impairment

Communicating effectively with people who are blind or vision impaired

- Identify yourself-do not assume someone will recognise you by your voice; use your full name and indicate your role in their care

- Face the person directly and use their name when introducing yourself or directing conversation to them in a group

- Speak naturally and clearly: loss of eyesight does not mean loss of hearing

- Do not expect eye contact or assume that lack of eye contact means lack of attention to what you are saying

- Never channel conversation through a third person

- In a group setting, introduce the other people present

- Never leave a conversation without saying so

- Try to avoid situations where competing background noise may be a problem

- Ask the patient to describe their level of vision and if they require any help; remember, not all vision impaired patients wear dark glasses or use a guide dog or cane

- Continue to use non-verbal body language; this will affect the tone of your voice and adds useful information to someone who is vision impaired

- Use everyday language - do not avoid words like "see" or "look" or talking about activities such as watching television

- During a consultation, if an examination is needed, explain that physical contact may be required (or that eye drops may be used)

- If an interpreter or support worker is involved, ensure the patient is happy with their presence at each stage of the consultation

- Ensure the patient knows who is in the consulting room; for example, medical students or nurses-ask them to introduce themselves, indicate their role, and gain consent to remain

- Use accurate and specific language when giving directions. For example, "the door is on your left", rather than "the door is over there"; remember the person is unlikely to see non-verbal cues and gestures or information

- Always ask whether help is needed, for example, to be guided to another department

- Be aware that changing light levels can affect vision: bright sunlight may be a greater problem than dark corridors

- Explain where things are placed; for example, "your cup of tea is on the table directly in front of you"-or use the "clockface" method; for example, "it's on the plate at 3 o'clock"

- Offer to read any written materials aloud; identify exactly where signatures are required

- If providing information for later reference, ensure it is in an accessible format and ask about preferred format; for example, large print, audio, or electronic

Points to consider

- Clarify plans for follow-up-discuss format of information, to whom a letter should be addressed, appropriate telephone numbers, transport requirements, support worker, interpreter. If potentially sensitive information to be conveyed, should the patient return to the surgery to be informed verbally by the doctor?

- When visual impairment is diagnosed, share information with other health professionals who are involved in the patient's healthcare provision. "Flag" medical records to alert others to their needs and include the information in referral letters

- Be patient and recognise that extra time may be required for consultations
}

International Glaucoma Association, and Macular Disease Society.

Various sources of support are available for people with visual impairment. For example, a visit to the surgery or hospital could be less daunting if accompanied by a voluntary support worker. The concept of an eye care liaison officer is relatively recent. Where medication is needed, healthcare professionals should check that the patient is able to adhere to prescribed treatment. Request that pharmacists offer information in large print or audio format and offer compliance packs that can assist self administration of medication. Visually impaired patients may encounter difficulties with opening certain packaging, distinguishing different packaging and tablets from each other, and measuring liquids. Using eye drops and administering injections are not easy without good vision. Commercial systems of support can be accessed, including "talking labels" (simple electronic devices providing short pre-recorded audio messages attached to the medication package) and "pen friends" (pen-like devices that scan minute barcodes and convert information to audio format).

\section{Conclusion}

Doctors might consider journeying from home to the consulting room while blindfolded or wearing spectacles with semi-opaque lenses, to help them imagine the emotional background against which people with impaired vision present to healthcare services. If healthcare professionals do not recognise the unique needs of patients with impaired vision, access to good quality healthcare for this group of patients is impeded, whereas anticipation of their needs promotes wellbeing and limits disability. 


\section{Additional educational resources}

World Blind Union (Union Mondiale des Aveugles) (www.worldblindunion.org)-International non-governmental coalition of representatives from associations of blind people and agencies providing services to them. Members are grouped into seven geographical unions: Africa, Asia, Europe, East Asia/Pacific, Latin America, Middle East, and North America/Caribbean, and provide an international forum for the exchange of knowledge and experience in the field of blindness and vision impairment

Royal National Institute of Blind People (RNIB) (www.rnib.org.uk)—Information, support and advice to people with sight loss

Action for Blind People (www.actionforblindpeople.org.uk)—Practical help and support for blind and partially sighted people of all ages

SeeAbility (www.seeability.org)—Supports adults who are visually impaired with multiple disabilities (learning, physical, or mental health)

Guide Dogs for the Blind Association (www.guidedogs.org.uk/aboutus/whatwedo)_Provides mobility for blind and partially sighted people, educates, funds research

Calibre Audio Library (www.calibre.org.uk)—Free postal service of audio books for adults and children with sight problems, dyslexia, or other disabilities

National Talking Newspapers and Magazines (www.tnauk.org.uk)_Provides newspapers and magazines in audio and digital format

StyleAble (www.styleable.co.uk/about)—Lifestyle resource for blind and partially sighted people, who want to create their own image and personal style and feel confident

The Accessible Friends Network (www.tafn.org.uk)—Worldwide internet based computer support for people with blindness and partial sight

St Dunstans (www.st-dunstans.org.uk/about us/index.html)—Physical and emotional support for blind and visually impaired ex-service men and women

VISION 2020 UK (www.vision2020uk.org.uk)—Facilitates collaboration between national, regional, and international organisations in the UK that focus on vision impairment

Thomas Pocklington Trust (www.pocklington-trust.org.uk)—Housing, care, and support services for people with sight loss in the UK

The Torch Trust (www.torchtrust.org)—A Christian organisation with a worldwide vision for people with sight loss

The National Blind Children's Society (www.nbcs.org.uk/aboutus/Our-Work/195)_Provides services such as educational advocacy advice and support and information for families

See also www.ehow.co.uk/list_5886520_list-charities-blind.htm

AJ is employed by RNIB. MEC is partly funded by the Centre of Excellence for Public Health (Northern Ireland), a UKCRC Public Health Research Centre of Excellence. We thank the British Heart Foundation, Cancer Research UK, Economic and Social Research Council, Medical Research Council, Research and Development Office for the Northern Ireland Health and Social Services, and the Wellcome Trust, under the auspices of the UK Clinical Research Collaboration for funding.

Contributors: MEC, AJJ, and PMH contributed to the conception and design of the article. MEC wrote the first draft of the paper. All authors contributed to the literature search and re-drafting of the paper, revising it critically for important intellectual content and approving the final version to be published. MEC is the guarantor.

Competing interests: All authors have completed the Unified Competing Interest form at http://www.icmje.org/coi_disclosure.pdf (available on request from the corresponding author) and declare: no support from any organisation for the submitted work; no financial relationships with any organisations that might have an interest in the submitted work in the previous three years; no other relationships or activities that could appear to have influenced the submitted work.

Provenance and peer review: Not commissioned; externally peer reviewed.

\section{Patient consent obtained.}

World Health Organization. Visual impairment and blindness. Fact sheet. WHO, 2011 282.
2 Bosanquet N, Mehta P. Evidence base to support the UK Vision Strategy. RNIB and The Guide Dogs for the Blind Association. www.vision2020uk.org.uk/ukvisionstrategy/core/ core_picker/download.asp?id=16.

3 van den Broek EG, Janssen CG, van Ramshorst T, Deen L Visual impairments in people with severe and profound multiple disabilities: an inventory of visual functioning. $J$ Intellect Disabil Res 2006;50:470-5

4 Royal National Institute for the Blind. Key information and statistics. www.rnib.org.uk aboutus/Research/statistics/Pages/statistics.aspx.

5 Crews JE, Campbell VA. Vision Impairment and hearing loss among community-dwelling older Americans: implications for health and functioning. Am J Pub Health 2004:94:823-9.

6 Thurston M, Thurston A, McLeod J. Socio-emotional effects of the transition from sight to blindness. B J Visual Impair 2010;28:90-112.

7 Silverstone B. Aging, vision rehabilitation, and the family. In: Crews JE, Whittington FJ, eds. Vision loss in an aging society: a multidisciplinary perspective. AFB Press, 2000.

8 Rovner BW, Ganguli M. Depression and disability associated with impaired vision: the MoVies Project. J Am Geriatr Soc 1998:46:617-9.

9 Waern M, Rubenowitz E, Runeson B, Skoog I, Wilhelmson K, Allebeck P. Burden of illness and suicide in elderly people: casecontrol study. BMJ 2002;324:1355-7.

10 Ivers RQ, Cumming RG, Mitchell P and Attebo K. Visual impairment and falls in older adults: The Blue Mountain Study. J Am Geriat Soc 1998;46:58-64.

11 Lin MY, Gutierrez PR, Stone KL, Yaffe K, Ensrud KE, Fink HA, et al. Vision impairment and combined vision and hearing impairment predict cognitive and functional decline in older women. J Am Geriatr Soc 2004:52:1996-2002.

12 O'Day BL, Killeen M, lezzoni LI. Improving health care experiences of persons who are blind or have low vision: suggestions from focus groups. Am J Med Qual 2004;19:193-200.

13 Gilmour G, Schreiber C, Ewing C. An examination of the relationship between low vision and Charles Bonnet Syndrome. Can J Ophthalmol 2009;44:49-52.

14 Sibley E, Alexandrou B. Towards an inclusive health service: a research report into the availability of information for blind and partially sighted people. www.rnib.org.uk/aboutus/ Research/reports/2009andearlier/Access_Health.pdf.

15 Pearce E, Crossland MD, Rubin GS. The efficacy of low vision device training in a hospital-based low vision clinic. Br J Ophthalmol 2011;95:105-8.

Accepted: 12 January 2012

Cite this as: BMJ 2012;344:e542

(c) BMJ Publishing Group Ltd 2012 